\title{
Pharmacoeconomic Impact of Different Regimens to Prevent Cytomegalovirus Infection in Renal Transplant Recipients
}

\author{
Lukas Kielberger $^{\mathrm{a}}$ Mirko Bouda ${ }^{\mathrm{a}}$ Pavel Jindra ${ }^{\mathrm{b}}$ Tomas Reischig ${ }^{\mathrm{a}}$ \\ ${ }^{a}$ Department of Internal Medicine I, and ${ }^{b}$ Department of Hemato-Oncology, Charles University Medical School \\ and Teaching Hospital, Plzen, Czech Republic
}

\section{Key Words}

Cytomegalovirus disease $\cdot$ Renal transplantation •

Prevention strategies · Pharmacoeconomic analysis

\begin{abstract}
Background:The aim of this study was to determine the cost impact of four different strategies for prevention of cytomegalovirus (CMV) disease after renal transplantation. Methods: Hospitalization data and medical resource utilization data were prospectively collected alongside two randomized trials. In the first trial, the patients were randomized to 3-month prophylaxis with either oral ganciclovir (1 $\mathrm{g}$ t.i.d., $\mathrm{n}=36$ ) or valacyclovir ( $2 \mathrm{~g}$ q.i.d., $\mathrm{n}=35$ ), and to the control group $(n=12)$ managed by deferred therapy. In the second trial, the patients were randomly assigned to 3-month valacyclovir prophylaxis $(n=34)$ or preemptive therapy with valganciclovir ( $900 \mathrm{mg}$ b.i.d. for a minimum of 14 days, $n=36$ ) for significant CMV DNAemia. The cost analysis involved all real costs directly related to CMV during the first year after renal transplantation. Results: The mean CMV-associated costs per patient were EUR 4,581, 2,577, 4,968, and 8,050 in patients in the ganciclovir, valacyclovir, preemptive, and deferred therapy groups, respectively $(p<0.001)$. Valacyclovir prophylaxis was significantly less expensive than any other
\end{abstract}

regimen. The cost of one episode of CMV disease was EUR 7,510 per patient. Due to excessive incidence of CMV disease, deferred therapy was the most expensive strategy $(p<$ 0.001). Conclusions: Valacyclovir prophylaxis is less expensive strategy compared with any other regimen.

Copyright $\odot 2012$ S. Karger AG, Basel

\section{Introduction}

Cytomegalovirus (CMV) is one of the most common opportunistic infections after organ transplantation. The manifestation of CMV ranges from mild febrile illness to tissue-invasive disease characterized by hepatitis, pneumonitis, gastrointestinal disease, chorioretinitis or meningoencephalitis [1]. In renal transplant recipients, CMV disease is associated not only with considerable morbidity and mortality, but also with increased risk of acute rejection, interstitial fibrosis and tubular atrophy or chronic rejection, and finally impaired long-term graft and patient survival [2-8]. Direct and indirect effects of CMV infection are accompanied by increased hospital stay and excessive costs $[9,10]$.

Two approaches to prevent CMV disease are currently acceptable: universal prophylaxis or preemptive therapy

\section{KARGER \\ Fax +4161306 1234 \\ E-Mail karger@karger.ch}

www.karger.com (c) 2012 S. Karger AG, Basel

$1420-4096 / 12 / 0356-0407 \$ 38.00 / 0$

Accessible online at:

www.karger.com/kbr
Tomas Reischig, MD, $\mathrm{PhD}$

Department of Internal Medicine I

Charles University Medical School and Teaching Hospital

Alej Svobody 80, CZ-30460 Plzen (Czech Republic)

Tel. +420 377103 573, E-Mail reischig@fnplzen.cz 
$[11,12]$. Oral valacyclovir and (val)ganciclovir are the most common drugs used in prophylaxis with comparable efficacy [13-18]. However, there is no study directly comparing the economic point of view of all used strategies. Previous pharmacoeconomic analyses showed that CMV prophylaxis is a cost-effective intervention in either $\mathrm{D}+/ \mathrm{R}$ - (donor-positive/recipient-negative CMV serologic status pretransplant) or $\mathrm{R}+$ recipients [11, 12, 19-24]. Schnitzler et al. [24] performed retrospective analysis of Medicare costs during the first year after kidney transplantation considering sero pairing outcomes showing total payments of USD 24,269 in the D-/R-, USD 28,904 in the D+/R-, USD 28,823 in the D-/R+ and USD 29,997 in the $\mathrm{D}+/ \mathrm{R}+$ group. However, in this study no prophylaxis was given, and that is why it gives expected information about increased costs due to CMV infection. However, the study gives clear economic motivation in CMV management after transplantation. Legendre et al. [20] performed cost-effectiveness analysis during the first 6 months after transplantation showing advantage of valacyclovir prophylaxis in the D+/R- group. Khoury et al. [18] showed no significant difference when comparing costs of preemptive strategy with valganciclovir prophylaxis.

Our analysis of randomized trials offers comparison of costs in four different preventive regimens against CMV disease using calculation of direct expenses related to CMV infection in the first year after renal transplantation.

\section{Methods}

We conducted data from two open-label randomized trials [13, 14]. Exclusion criteria in both studies included D-/R- CMV serostatus, allergy to valacyclovir or ganciclovir, severe leukopenia or thrombopenia.

In the first study [13] in the period from April 1999 to January 2003, 81 patients were prospectively randomized to 3-month treatment with oral ganciclovir at a dose of $1 \mathrm{~g}$ t.i.d., $\mathrm{n}=35$ (Cymevene, Hoffmann-La Roche, UK) or oral valacyclovir (2 g q.i.d., $\mathrm{n}=34$; Valtrex Glaxo Wellcome, UK). The control group $(\mathrm{n}=12)$ was managed by deferred therapy. In this group, the patients were monitored for CMV DNAemia and treated with intravenous ganciclovir if early signs of CMV disease occurred. Enrollment of patients in the control group was stopped for ethical reasons due to excess rate of CMV disease, and from January 2001, patients were randomized into the valacyclovir only or the ganciclovir only group. In all groups, CMV activity was monitored using PCR for CMV DNA once per week over first 15 weeks after transplantation and then at months 5 and 6 after transplantation.

In the second trial [14] in the period from October 2003 to $\mathrm{Au}$ gust 2006, 70 renal transplant recipients were randomized to 3-month prophylaxis with valacyclovir (2 g q.i.d., $\mathrm{n}=34$ ) or preemptive therapy with valganciclovir (Valcyte, Hoffmann-La Roche, Germany) $900 \mathrm{mg}$ b.i.d. for a minimum of 14 days $(\mathrm{n}=36)$ for significant CMV DNAemia ( $\geq 2,000$ copies/ml by quantitative PCR in whole blood) assessed once a week for 16 weeks and subsequently at 5, 6, 9 and 12 months. In both studies, the drug dosages were adjusted according to renal function.

CMV disease was defined as a symptomatic CMV infection comprising CMV syndrome or tissue-invasive CMV disease. In both studies, CMV disease was treated by intravenous ganciclovir (Cymevene, Hoffmann-La Roche, Switzerland) at a dose of $5 \mathrm{mg} /$ $\mathrm{kg}$ every $12 \mathrm{~h}$ for a minimum of 3 weeks. In the second study, once the clinical state had improved, patients could be switched to oral valganciclovir (Valcyte, Hoffmann-La Roche, Germany). The duration of therapy was 21 days or longer in cases with persistent CMV viremia.

\section{Immunosuppression Regimen}

Immunosuppression was based on cyclosporine (Neoral; Novartis, Switzerland) or tacrolimus (Prograf; Fujisawa Killorglin Co., Kerry, Ireland). Patients with high immunologic risk received induction therapy with rabbit antithymocyte globulin (Fresenius, Germany) or OKT3 (Orthoclone, Cilag, Switzerland). Recipients of highly marginal donors (hypertension, biopsy-proven nephrosclerosis, age $>70$ years, donors after cardiac death) were treated with anti-IL2R monoclonal antibody (Simulect, Novartis, Switzerland) and with low-dose sirolimus (Rapamune; Wyeth Laboratories, UK). All patients received corticosteroids, and all except 2 were given mycophenolate mofetil (Cellcept, Hoffmann-La Roche, Switzerland). Episodes of acute rejection were treated initially with high-dose methylprednisolone (SoluMedrol, Pfizer, Greece). Steroid-resistant episodes were treated by rabbit antithymocyte globulin (Fresenius, Germany) or OKT3 (Orthoclone).

\section{Statistical Analysis}

Qualitative data were compared using Fisher's exact test; quantitative data were compared using one-way analysis of variance for parametric data, and Kruskal-Wallis test for nonparametric data. For pairwise comparison, Dunn's method and MannWhitney test were used. Survival data were analyzed using Kaplan-Maier survival analysis. Pairwise comparison was performed using the Holm-Sidak method. A significance level of $<0.05$ was set for all tests.

\section{Pharmacoeconomic Analysis}

The pharmacoeconomic analysis embraced expenses directly associated with overall CMV management including costs of diagnosis and treatment of CMV disease, drugs used for prophylaxis or preemptive therapy, PCR monitoring, diagnostic procedures in CMV viremia, and costs associated with physicians and nursing time and hotel services in hospital. The costs during hospital stay due to CMV disease were directly obtained from hospital charges to healthcare insurance company of each patient. While CMV PCR monitoring is not necessary for clinical management during prophylactic period, costs in the prophylactic arms were analyzed without PCR monitoring and its associated costs during the course of prophylaxis (first 3 months). The drug costs were calculated on each patient's actual dose adjusted to renal function given during prophylaxis in actual pric- 
Fig. 1. Allocation of patients to different groups in the study.

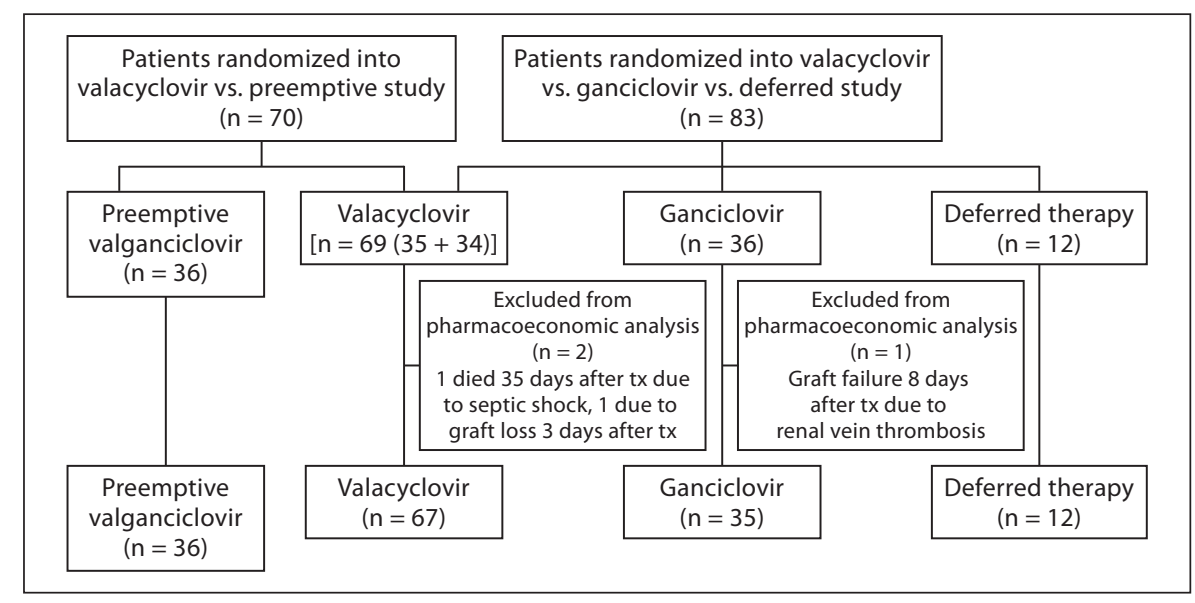

es in 2010. Costs are expressed in EUR using the mean exchange rate between the Czech crown and the euro during 2010. Drug costs were calculated to be EUR 0.91 per valacyclovir $500 \mathrm{mg}$ tablet, EUR 4.8 per ganciclovir $250 \mathrm{mg}$ tablet, EUR 21.7 per 450 $\mathrm{mg}$ valganciclovir tablet, and EUR 54.8 per $500 \mathrm{mg}$ intravenous ganciclovir. Costs for PCR monitoring were EUR 125 per test. Assessment of pp65 antigenemia was EUR 59.1 per procedure, serology of CMV was EUR 92.4 and CMV blood culture was EUR 81.8. Special diagnostic procedures (colonoscopy, bronchoscopy, biopsy analysis) were calculated for actual costs in official 2010 tariff rates set by Czech Department of Healthcare. Hotel service during extra days of hospitalization due to CMV disease was calculated as EUR 43/day, which is a standardized payment from Czech healthcare insurance companies. Extra ambulatory visits were calculated as EUR 5.3 for physicians and nursing time.

\section{Sensitivity Analysis}

Sensitivity analysis was performed to simulate the impact of changing prices of PCR monitoring or pharmacotherapy on total costs in different prophylactic regimens. This analysis modeled 4 different situations using different prices of PCR monitoring and pharmacotherapy. These calculations assumed the variation in costs of PCR from EUR 37.8 to 264.5 per procedure, while costs of medication were constant. This cost of PCR is an approximation of Medicare reimbursement and the price of US national reference laboratory. Another calculation was performed using varying prices of pharmacotherapy and constant costs of PCR monitoring. In this analysis, the cost of valacyclovir varied from EUR 0.65 to 1.9 per $500 \mathrm{mg}$ tablet; similarly the cost of ganciclovir varied from EUR 2.3 to 7.4 per $250 \mathrm{mg}$ tablet, and valganciclovir costs varied between EUR 8.3-22.7 per $450 \mathrm{mg}$ tablet. Costs were taken from the actual pricing of original drugs and generics available on the market in 2010. To simulate differences in US healthcare system with much higher hospitalization costs and physician/nurse fee, we calculated economic analysis assuming the cost of EUR 2,721 per one hospitalization day due to CMV disease and physician/nurse monitor fee of EUR 38 per test $[25,26]$.

Pharmacoeconomics of CMV Prevention

\section{Results}

A total of 150 patients were enrolled in the analysis. Allocation to different groups is presented in figure 1. The groups did not differ in demographic characteristics, CMV serostatus or immunosuppressive therapy, except in higher use of cyclosporine-based immunosuppression between the valacyclovir and preemptive groups. Patient characteristics are presented in table 1 . Three patients were excluded from economic analysis: 2 patients from the valacyclovir group (one patient experienced graft loss 3 days after transplantation, the other died due to septic shock 35 days after transplantation) and one patient from the ganciclovir group (graft failure 8 days after transplantation due to renal vein thrombosis). Sixty-seven patients were treated in the valacyclovir group, 35 patients in the ganciclovir group, 36 patients were enrolled in the preemptive group and 12 were managed by deferred therapy.

There were no significant differences in the distribution of the induction and maintenance immunosuppressive regimen between groups. The most commonly used maintenance regimen was cyclosporine with mofetil mycophenolate, followed by combination of tacrolimus and mofetil mycophenolate. In the valacyclovir group, mean daily dose of valacyclovir was $5.61 \pm 1.37 \mathrm{~g}$. Mean duration of prophylaxis was $91 \pm 10$ days. In the ganciclovir group, mean daily dose was $1.44 \pm 0.73 \mathrm{~g}$, mean duration of prophylaxis was $88 \pm 15$ days. In the preemptive group, 13 patients were treated with valganciclovir. Three of these patients required repeated therapy because of DNAemia recurrence. A total of 21 courses were applied. The mean duration of therapy was $35 \pm 40$ days per patient ( $22 \pm 11$ days per course), with the mean daily valganciclovir dose of $980 \pm 190 \mathrm{mg}$. 
Table 1. Baseline recipient and donor characteristics

\begin{tabular}{|c|c|c|c|c|c|}
\hline Recipient characteristics & $\begin{array}{l}\text { Ganciclovir } \\
(\mathrm{n}=35)\end{array}$ & $\begin{array}{l}\text { Valacyclovir } \\
(\mathrm{n}=67)\end{array}$ & $\begin{array}{l}\text { Preemptive } \\
(\mathrm{n}=36)\end{array}$ & $\begin{array}{l}\text { Deferred } \\
(\mathrm{n}=12)\end{array}$ & $\mathrm{p}$ \\
\hline Age, years & $48 \pm 12$ & $46 \pm 12$ & $50 \pm 13$ & $46 \pm 13$ & 0.531 \\
\hline Males & $26(74)$ & $52(78)$ & $28(78)$ & $8(67)$ & 0.462 \\
\hline \multicolumn{6}{|l|}{ Cause of renal disease } \\
\hline Chronic glomerulonephritis & $22(63)$ & $38(57)$ & $15(42)$ & $5(42)$ & 0.211 \\
\hline Chronic interstitial nephritis & $4(11)$ & $7(10)$ & $5(14)$ & $5(42)$ & 0.015 \\
\hline Diabetic nephropathy & $1(3)$ & $4(6)$ & $5(14)$ & 0 & 0.199 \\
\hline Polycystic kidney disease & $3(9)$ & $8(12)$ & $6(17)$ & $2(17)$ & 0.478 \\
\hline Hypertensive nephrosclerosis & $5(14)$ & $5(8)$ & $5(14)$ & 0 & 0.483 \\
\hline Other & 0 & $5(8)$ & 0 & 0 & 0.23 \\
\hline Previous transplantation & $4(11)$ & $7(10)$ & $3(8)$ & $2(17)$ & 0.587 \\
\hline \multicolumn{6}{|l|}{ Immunosuppression } \\
\hline Cyclosporine-based regimen & $33(94)$ & $57(85)$ & $25(69)$ & $12(100)$ & $0.003^{*}$ \\
\hline Tacrolimus-based regimen & $2(6)$ & $8(12)$ & $6(17)$ & 0 & 0.260 \\
\hline Non-CNI regimen & 0 & $2(3)$ & $5(14)$ & 0 & 0.054 \\
\hline Maintenance mofetil mycophenolate therapy & $32(89)$ & $65(97)$ & $36(100)$ & $12(100)$ & 0.493 \\
\hline Maintenance sirolimus therapy & $3(8)$ & $9(13)$ & $5(14)$ & 0 & 0.312 \\
\hline Maintenance azathioprine therapy & $1(3)$ & $1(2)$ & 0 & 0 & 0.115 \\
\hline OKT3 or ATG induction & $5(14)$ & $8(12)$ & $4(11)$ & $2(17)$ & 0.587 \\
\hline \multicolumn{6}{|l|}{ CMV serostatus } \\
\hline $\mathrm{D}+/ \mathrm{R}-$ & $5(14)$ & $8(12)$ & $6(17)$ & $1(8)$ & 0.662 \\
\hline $\mathrm{D}+/ \mathrm{R}+$ & $27(77)$ & $48(72)$ & $23(64)$ & $8(67)$ & 0.300 \\
\hline $\mathrm{D}-/ \mathrm{R}+$ & $3(9)$ & $11(16)$ & $7(19)$ & $3(25)$ & 0.307 \\
\hline Donor type & & & & & 0.726 \\
\hline Deceased & $33(94)$ & $65(97)$ & $34(96)$ & $12(100)$ & \\
\hline Living & $2(6)$ & $2(3)$ & $2(6)$ & 0 & \\
\hline Donor age, years & $46 \pm 13$ & $43 \pm 15$ & $43 \pm 16$ & $47 \pm 15$ & 0.693 \\
\hline
\end{tabular}

Figures are mean $\pm \mathrm{SD}$ or $\mathrm{n}(\%) .{ }^{*} \mathrm{p}<0.05$, valacyclovir vs. preemptive group.

Table 2. Patient and graft survival characteristics

\begin{tabular}{llllll}
\hline & $\begin{array}{l}\text { Ganciclovir } \\
(\mathrm{n}=35)\end{array}$ & $\begin{array}{l}\text { Valacyclovir } \\
(\mathrm{n}=67)\end{array}$ & $\begin{array}{l}\text { Preemptive } \\
(\mathrm{n}=36)\end{array}$ & $\begin{array}{l}\text { Deferred } \\
(\mathrm{n}=12)\end{array}$ & $\mathrm{p}$ \\
\hline Twelve-month survival, \% & 94 & 96 & 100 & 100 & 0.485 \\
Twelve-month graft survival, \% & 86 & 93 & 94 & 92 & 0.603 \\
Incidence of biopsy-proven acute rejection & $12(34)$ & $9(13)$ & $13(36)$ & $7(58)$ & $<0.05^{\mathrm{a}}$ \\
\hline
\end{tabular}

Figures in parentheses indicate percentages.

a Multiple pairwise comparison showed significant difference in the incidence of acute rejection in the valacyclovir group as compared to any other group.

\section{Main Clinical Outcomes}

Patient and graft survival was similar in all groups (table 2). Five patients died during the study period. There were three deaths in the valacyclovir group due to invasive aspergillosis, acute necrotizing pancreatitis, and septic shock, respectively. In the ganciclovir group, there were two deaths. The first patient died of a pulmonary embolism, the second of sudden cardiac death after cardiac surgery. Both died with a functioning graft.

One-year graft survival was $93 \%$ in the valacyclovir group, $86 \%$ in the ganciclovir group, $94 \%$ in the preemptive group, and $92 \%$ in the deferred group. The incidence 
Table 3. CMV infection characteristics

\begin{tabular}{llllll}
\hline & $\begin{array}{l}\text { Ganciclovir } \\
(\mathrm{n}=35)\end{array}$ & $\begin{array}{l}\text { Valacyclovir } \\
(\mathrm{n}=67)\end{array}$ & $\begin{array}{l}\text { Preemptive } \\
(\mathrm{n}=36)\end{array}$ & $\begin{array}{l}\text { Deferred } \\
(\mathrm{n}=12)\end{array}$ & $\mathrm{p}$ \\
\hline Incidence of CMV viremia $^{\mathrm{a}}$ & $10(29)$ & $30(45)$ & $33(92)$ & $11(92)$ & $<0.05^{\mathrm{b}}$ \\
Incidence of CMV disease $^{\mathrm{a}}$ & $2(6)$ & $4(6)$ & $2(6)$ & $8(67)$ & $<0.05^{\mathrm{c}}$ \\
CMV syndrome, number of episodes $_{\text {CMV tissue invasive disease, number of episodes }}$ & 1 & 2 & 4 & 11 & \\
\hline
\end{tabular}

Figures in parentheses indicate percentages.

${ }^{a}$ More than 1 episode of CMV viremia/disease may occur in a single patient.

${ }^{\mathrm{b}}$ Multiple pairwise comparison showed significant difference in CMV viremia incidence in preemptive and deferred group $(\mathrm{p}<0.05)$.

${ }^{c}$ Multiple pairwise comparison showed significant difference in CMV disease incidence in deferred group $(\mathrm{p}<0.05)$.

Table 4. Analysis of CMV-related costs (ANOVA on ranks)

\begin{tabular}{|c|c|c|c|c|c|}
\hline & $\begin{array}{l}\text { Ganciclovir } \\
(\mathrm{n}=35)\end{array}$ & $\begin{array}{l}\text { Valacyclovir } \\
(\mathrm{n}=67)\end{array}$ & $\begin{array}{l}\text { Preemptive } \\
(\mathrm{n}=36)\end{array}$ & $\begin{array}{l}\text { Deferred } \\
(\mathrm{n}=12)\end{array}$ & $\mathrm{p}$ \\
\hline \multicolumn{6}{|l|}{ Total CMV-related expenses } \\
\hline Mean $\pm \mathrm{SD}$ & $4,581 \pm 2,982$ & $2,577 \pm 3,606$ & $4,968 \pm 4,825$ & $8,050 \pm 6,432$ & \multirow[t]{2}{*}{$<0.001^{\mathrm{a}}$} \\
\hline Median & 4,102 & 2,034 & 3,018 & 6,621 & \\
\hline \multicolumn{6}{|l|}{ Costs for PCR monitoring } \\
\hline Mean \pm SD & $530 \pm 319$ & $617 \pm 324$ & $2,694 \pm 538$ & $2,412 \pm 478$ & \multirow[t]{2}{*}{$<0.001^{\mathrm{b}}$} \\
\hline Median & 376 & 627 & 2,506 & 2,443 & \\
\hline \multicolumn{6}{|c|}{ Costs of drugs used for prophylaxis or preemptive therapy } \\
\hline Mean \pm SD & $3,387 \pm 1,857$ & $1,299 \pm 342$ & $888 \pm 2,435$ & & \multirow[t]{2}{*}{$<0.001$} \\
\hline Median & 2,884 & 1,381 & 0 & & \\
\hline \multicolumn{6}{|l|}{ Total drug costs } \\
\hline Mean $\pm S D$ & $3,680 \pm 2,004$ & $1,577 \pm 1,820$ & $1,399 \pm 3,184$ & $2,790 \pm 3,756$ & \multirow[t]{2}{*}{$<0.001$} \\
\hline Median & 3,485 & 1,409 & 0 & 1,322 & \\
\hline Cost for CMV disease, mean $\pm \mathrm{SD}$ & $611 \pm 2,843$ & $595 \pm 3,532$ & $1,086 \pm 4,565$ & $6,656 \pm 7,058$ & $<0.001^{\mathrm{c}}$ \\
\hline \multicolumn{6}{|c|}{$\begin{array}{l}\text { Kruskal-Wallis one-way ANOVA on ranks. Costs in EUR in } 2010 \text {. Deferred group was excluded from pro- } \\
\text { phylactic drug costs calculation. No prophylaxis was given in this group. } \\
\text { a Multiple pairwise comparison showed significant difference in valacyclovir group when compared to any } \\
\text { other regimen }(\mathrm{p}<0.05) \text {. } \\
\text { b Multiple pairwise comparison showed significant difference when comparing both prophylactic regimens } \\
\text { with preemptive or deferred strategy }(\mathrm{p}<0.05) \text {. } \\
\text { c Multiple pairwise comparison showed significant difference in deferred strategy when compared to any } \\
\text { other regimen }(\mathrm{p}<0.05) \text {. }\end{array}$} \\
\hline
\end{tabular}

of biopsy-proven acute rejection was significantly lower in the valacyclovir group when compared to other regimens $(14 \%$ in the valacyclovir group vs. $34 \%$ in the ganciclovir group vs. $36 \%$ in the preemptive group vs. $58 \%$ in the deferred group; $\mathrm{p}<0.05$ ).

The characteristics of CMV infection are summarized in table 3. Cumulative incidence of CMV viremia within the first 12 months was $45 \%$ in the valacyclovir group, $29 \%$ in the ganciclovir group, which was significantly lower than in both preemptive $(92 \% ; \mathrm{p}<0.05)$ and in the deferred therapy $(92 \% ; \mathrm{p}<0.05)$ groups. During the first 12 months after transplantation there were two episodes of CMV disease in the ganciclovir group in 2 patients (6\%), four episodes in the valacyclovir group in 4 patients 
Table 5. Sensitivity analysis (ANOVA on ranks)

\begin{tabular}{|c|c|c|c|c|c|}
\hline Total costs & $\begin{array}{l}\text { Ganciclovir } \\
(\mathrm{n}=35)\end{array}$ & $\begin{array}{l}\text { Valacyclovir } \\
(\mathrm{n}=67)\end{array}$ & $\begin{array}{l}\text { Preemptive } \\
(\mathrm{n}=36)\end{array}$ & $\begin{array}{l}\text { Deferred } \\
(\mathrm{n}=12)\end{array}$ & $\mathrm{p}$ \\
\hline \multicolumn{6}{|c|}{ EUR 45 for PCR test } \\
\hline Mean $\pm S D$ & $4,232 \pm 2,850$ & $2,178 \pm 3,449$ & $3,242 \pm 4,575$ & $6,015 \pm 6,523$ & \multirow[t]{2}{*}{$<0.001$} \\
\hline Median & 3,850 & 1,659 & 1,380 & 4,352 & \\
\hline \multicolumn{6}{|c|}{ EUR 264 for PCR test } \\
\hline Mean $\pm \mathrm{SD}$ & $5,346 \pm 3,921$ & $3,476 \pm 3,960$ & $8,906 \pm 5,403$ & $13,805 \pm 8,653$ & $<0.001$ \\
\hline \multicolumn{6}{|c|}{ Minimal costs for pharmacotherapy ${ }^{\mathrm{a}}$} \\
\hline Mean $\pm \mathrm{SD}$ & $2,778 \pm 2,777$ & $1,926 \pm 2,659$ & $4,192 \pm 3,445$ & $7,243 \pm 5,080$ & \multirow[t]{2}{*}{$<0.001$} \\
\hline Median & 2,243 & 1,450 & 2,968 & 6,603 & \\
\hline \multicolumn{6}{|c|}{ Maximal costs for pharmacotherapy ${ }^{b}$} \\
\hline Mean $\pm S D$ & $6,359 \pm 3,451$ & $3,800 \pm 3,673$ & $4,971 \pm 4,904$ & $8,072 \pm 6,490$ & \multirow[t]{2}{*}{$<0.001$} \\
\hline Median & 3,319 & 5,902 & 2,968 & 6,603 & \\
\hline \multicolumn{6}{|c|}{ Total costs from US healthcare perspective ${ }^{c}$} \\
\hline \multicolumn{6}{|c|}{$\begin{array}{l}\text { a Cost used in calculation: valacyclovir EUR } 0.57 \text { per } 500 \mathrm{mg} \text { tablet, ganciclovir EUR } 2.24 \text { per } 250 \text { mg tablet, valganciclovir EUR } \\
1 \text { per } 450 \mathrm{mg} \text { tablet. } \\
{ }^{\mathrm{b}} \text { Cost used in calculation: valacyclovir EUR } 1.8 \text { per } 500 \mathrm{mg} \text { tablet, ganciclovir EUR } 7.3 \text { per } 250 \text { mg tablet, valganciclovir EUR } 22.4 \\
\text { er } 450 \mathrm{mg} \text { tablet. } \\
\text { c Cost used in calculation: EUR 2,721 per one hospitalization day due to CMV disease and physician/nurse monitor fee of EUR } 38 \\
\text { er test. }\end{array}$} \\
\hline
\end{tabular}

(6\%), five episodes in the preemptive group in 2 patients $(6 \%)$, and 13 episodes in the deferred group in 8 patients $(67 \% ; \mathrm{p}<0.05)$.

\section{CMV-Related Cost Analysis}

All relevant economic data are summarized in table 4 . Total directly CMV-related costs were EUR 4,581 in the ganciclovir group, EUR 2,577 in the valacyclovir group, EUR 4,968 in the preemptive group, and EUR 8,050 in the deferred group $(\mathrm{p}<0.001)$. Valacyclovir therapy remains the cheapest regimen compared to all other regimens $(\mathrm{p}<0.05)$. Similarly, in $\mathrm{D}+/ \mathrm{R}-$ group, valacyclovir prophylaxis was of the lowest price. However, the small number of patients precludes relevant statistical analysis (online suppl. table 1 , for all online suppl. material, see www.karger.com/doi/10.1159/000335962). Main determinants of total expenses were drug-related costs and costs for PCR monitoring. In both prophylaxis groups, the drug costs were the main components of the total price. On the other hand, in the preemptive group, the main cost component was the price of PCR analyses. The cost for PCR was EUR 530 in the ganciclovir group, EUR 617 in the valacyclovir group, EUR 2,694 in the preemp- tive, and EUR 2,412 in the deferred therapy ( $<<0.001)$. Preemptive therapy and deferred therapy have excessively higher PCR costs compared either with ganciclovir or valacyclovir prophylaxis $(\mathrm{p}<0.05)$.

The excessive costs in the deferred group are explained by huge expenses due to the high incidence of CMV disease in this group. Average costs of one episode of CMV disease were EUR 7,510, while the costs of CMV disease management (all episodes included) in patients with CMV disease were EUR 11,205 per patient. The costs were similar in the deferred therapy group and other preventive regimens (EUR 9,931 vs. 12,479, p = NS). Due to lower price of drug with comparable clinical effectiveness [7, 9], the valacyclovir prophylaxis was the cheapest strategy.

\section{Sensitivity Analysis}

Two main components of total costs (costs for PCR diagnostics and costs for drugs) were chosen as input parameters in the sensitivity analysis. Results of sensitivity analysis are detailed in table 5 . Change in price of PCR procedure has the biggest impact on total costs in the preemptive or the deferred regimen. The first model situation shows estimated costs when PCR is EUR 45.3 per 
analysis (Medicare reimbursement). In this situation, valacyclovir regimen still remains the cheapest strategy. There is also a significant decrease in total costs in the preemptive group and in the deferred group. In the model when PCR is EUR 264.5 per one test (charge by US National reference laboratory), we show increased cost, mainly in the preemptive and deferred regimens. The incremental cost is EUR 3,938 in the preemptive and EUR 5,755 in the deferred strategy when compared to the real costs $(\mathrm{p}<0.001, \mathrm{p}=0.07$, respectively).

Similarly, changing drug costs have the biggest impact on total costs in both prophylactic regimens. In the model with the lowest market drug prices (e.g. using generic drugs), there is a significant reduction in the ganciclovir group (EUR 1,803, p < 0.001). Analogously, we modeled the situation with the highest prices of the drug therapy. In this model situation, there is a significant increase in both prophylactic groups $(\mathrm{p}<0.05)$. In contrast, high drug prices had negligible effect on total CMV-related costs in the preemptive or the deferred strategy. Nevertheless, according to our data, deferred therapy remains the most expensive strategy in all these model situations.

In the model simulating US healthcare perspective with high hospitalization costs, we noted excessive increase in costs in deferred therapy (EUR 54,321). Again, valacyclovir prophylaxis remained the cheapest strategy (EUR 4,883, p < 0.001).

\section{Discussion}

Our study evaluated the direct costs of CMV management in the first year after transplantation. All calculations are based on real resource use for each patient: exact amount of drugs used, number of CMV diagnostic tests, duration of hospitalization, etc. Expression in 2010 prices brings data closer to current economic situation and limits the potential bias caused by different time periods of two studies.

Both prophylactic regimens and preemptive therapy have comparable efficacy in CMV disease prevention. The study has shown that valacyclovir prophylaxis is the cheapest strategy. Deferred therapy remains the most expensive strategy. The main disadvantage of deferred therapy is excessive cost of CMV disease management, while 13 episodes occurred in this group. The high incidence of CMV disease in the deferred group is comparable to other reported data [27]. It should be pointed out that conclusions regarding the deferred therapy are limited by the small sample size. Also valganciclovir was not available

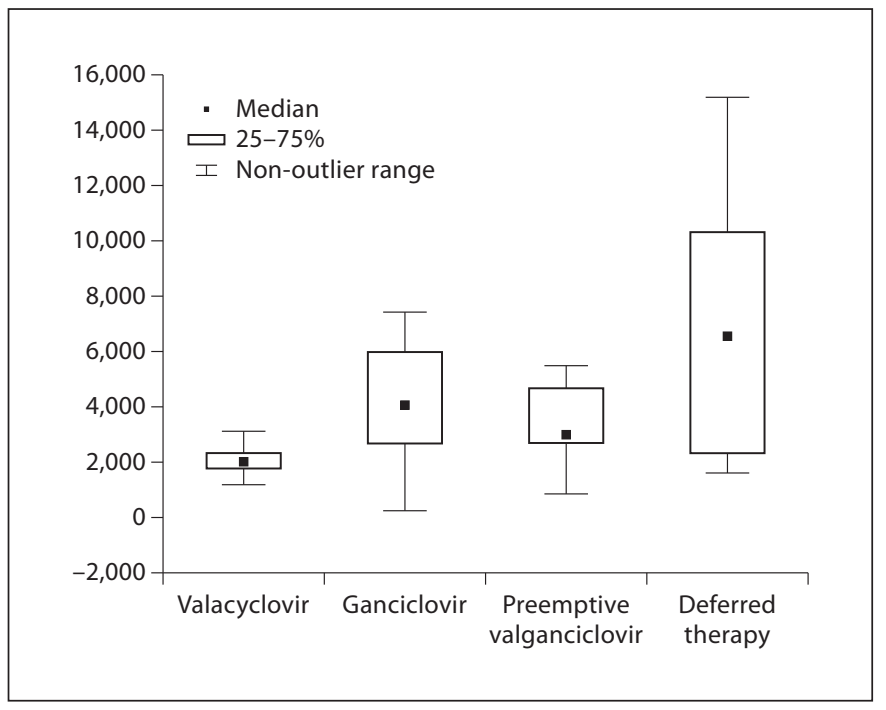

Fig. 2. Total charges associated with CMV infection in the first 12 months after transplantation.

in the early period of the study, which may result in higher costs in the deferred therapy group. However, the costs for CMV disease per patient in the deferred group did not differ when compared to other preventive regimens.

The high incidence of asymptomatic CMV viremia in preemptive or deferred therapy groups is likely due to high-sensitivity (lower detection limit of 50 copies $/ \mathrm{ml}$ of whole blood) PCR used in our study. Likewise, in studies with similar methodology, asymptomatic CMV viremia occurred up to $100 \%$ even in $\mathrm{R}+$ patients [27].

One episode of CMV disease costs EUR 7,510. Costs of one episode of CMV disease are lower compared to published data due to lower costs of hospitalization service in Czech healthcare system. Legendre et al. [28] calculated the price of one episode of CMV syndrome as EUR 10,852, and that of CMV tissue invasive disease as EUR 15,431. Hospitalization costs represent $59 \%$ of total expenses. One hospitalization day in their study was calculated to cost EUR 537. This excessive cost of hospitalization is not explained in the paper.

The economic benefit of valacyclovir prophylaxis is based on low costs of the drug given when reaching the same clinical effect. In the valacyclovir group, the drug costs represented $61 \%$ of total expenses. In the ganciclovir group, the prophylactic drug costs represented $80 \%$ of the total costs. The costs excluding prophylaxis in the valacyclovir and ganciclovir groups are similar (EUR 1,278 with valacyclovir and EUR 1,194 with ganciclovir). Total 
expenses of the preemptive therapy are less acceptable due to high costs of PCR monitoring, which represents $54 \%$ of the total costs in combination with the relatively high price of valganciclovir used for treatment of asymptomatic CMV viremia.

Sensitivity analysis modeled four different cost situations, and shows significant cost drop in the preemptive group when the lowest price of PCR is available. When calculating the lowest drug costs actually available on the market, there is a cost drop in the ganciclovir group, but valacyclovir still remains the cheapest strategy. As presumed, there is no significant cost change in the preemptive and deferred groups when modeling different pharmacotherapy prices, while in these groups diagnostic procedures represent the majority of the costs.

Prophylactic and preemptive valganciclovir treatment was compared in a recent trial [18]. This calculation expresses total costs at USD 7,130 in the preemptive valganciclovir regimen compared to USD 7,678 in valganciclovir prophylaxis with no statistically significant difference. The cost difference compared to our study is caused by using more expensive monitoring and higher charges for nursing and physician time in US healthcare system. Legendre et al. [28] compared deferred strategy, preemptive therapy, and valacyclovir and ganciclovir prophylaxis assuming costs in 6 months after transplantation. This study showed lower costs in the deferred group (EUR $6,017)$ due to lower incidence of CMV disease in this group (45\%). Preemptive therapy was the most expensive strategy in this analysis due to high expenses for monitoring and pharmacotherapy (EUR 10,241). Nevertheless, similar to our results, this analysis showed the superiority of oral valacyclovir prophylaxis due to low costs for pharmacotherapy with similar clinical efficacy compared to ganciclovir.

Several studies used economic models (such as Markov model) to compare the cost-effectiveness and quality-adjusted life years using calculation of relative risk of various events and its impact on patient and graft survival. Even this type of analysis shows benefits of CMV prophylaxis either in the $\mathrm{D}+/ \mathrm{R}$ - group or in the $\mathrm{R}+$ group compared with deferred strategy. Limitation of these data might be seen in the construction of Markov process by itself when using data and probabilities from many different studies [19]. In contrast, our data are derived from actual clinical setting rather than modeling to demonstrate exact cost-effectiveness of each prophylactic regimen.

Our study is not able to directly compare valganciclovir prophylaxis with other regimens based on our origi- nal data. In the model calculation flowing from ganciclovir group data, when each $1.5 \mathrm{~g}$ of ganciclovir is substituted by $450 \mathrm{mg}$ of valganciclovir, the total cost of prophylactic drugs would be EUR 2,178, which is lower than ganciclovir cost (EUR 3,387). It must be noted that this calculation is not based on a real situation and may include systematic error. A new prospective trial is needed for further analysis of the cost-effectiveness of valganciclovir prophylaxis compared to other regimens. The efficacy of valganciclovir in terms of CMV disease prevention is comparable to oral ganciclovir [29]. Similarly, valacyclovir is considered as an equivalent strategy in CMV prevention when compared to ganciclovir in renal transplant recipients $[13,17]$.

Our study analyzed economic impact of 3-month prophylaxis only. A recently published randomized trial proved the clinical superiority of 6 -month valganciclovir prophylaxis compared to a 3-month course in high-risk renal transplant recipients [30]. Cost-effectiveness analyses showed the advantage of 6-month prophylaxis in quality-adjusted life years in a 5- to 10 -year period using Markov model [25, 31]. However, the limitation of such analyses lies in the use of clinical probabilities of graft failure and death in association with CMV disease from different studies, which may vary significantly among different transplant centers or immunosuppressive regimens.

Our study was a single-center trial which allowed for internal consistency in cost calculation and in CMV disease diagnosis. The main advantage of our study is its prospective design using data from randomized controlled trials. Moreover, real costs directly related to the management of CMV were available for analyses. Nevertheless, there are important limitations which should be considered for proper interpretation of our results. Compared to published trials, our analysis does not involve a sufficient number of $\mathrm{D}+/ \mathrm{R}$ - patients, and the results of prophylaxis may differ. Both the incidence and severity of CMV disease is higher in the D+/R- subgroup. Moreover, direct comparison of prophylaxis and preemptive therapy has not been published. Therefore, our results are not applicable to population at risk of primary CMV infection. The costs are dependent on clinical outcomes such as incidence of CMV disease which may differ in various centers. Our single-center economic data must be interpreted with caution in transplant programs with substantially different clinical outcomes. As mentioned above, our economic analysis does not include long-term indirect impacts of CMV infection after transplantation (possible cost savings from improved graft survival), and 
also excludes costs outside of healthcare system such as time lost from work. Another limitation is impossibility of calculation of additional costs of CMV-induced acute rejection, while it was difficult to distinguish between rejection triggered by $\mathrm{CMV}$ and rejection due to other causes. Apparently, presumption of the relationship between CMV and development of interstitial fibrosis and tubular atrophy and other forms of chronic rejection implies higher expenses in patients without CMV prophylaxis [32].

\section{Conclusion}

We have shown valacyclovir prophylactic regimen to be economically superior compared to other prophylactic regimens due to low price of pharmacotherapy and similar clinical efficacy to oral ganciclovir prophylaxis or pre- emptive strategy. Even in sensitivity analysis modeling different economic situations, valacyclovir remains the cheapest strategy. In contrast, deferred therapy remains the most expensive strategy in CMV management. However, the limitations, namely small sample size and inaccessibility of valganciclovir, must be taken into account.

\section{Acknowledgments}

The study was supported by the research project number MSM0021620819 'Replacement of and support to some vital organs' awarded by Ministry of Education, Youth and Physical training of the Czech Republic.

\section{Disclosure Statement}

The authors declare no competing interests.

\section{References}

1 Fishman JA: Infection in solid-organ transplant recipients. N Engl J Med 2007;357: 2601-2614.

-2 Sagedal S, Hartmann A, Nordal KP, et al: Impact of early cytomegalovirus infection and disease on long-term recipient and kidney graft survival. Kidney Int 2004;66:329-337.

-3 Sagedal S, Rollag H, Hartmann A: Cytomegalovirus infection in renal transplant recipients is associated with impaired survival irrespective of expected mortality risk. Clin Transplant 2007;21:309-313.

-4 Reischig T, Jindra P, Svecova M, Kormunda S, Opatrný K Jr, Treska V: The impact of cytomegalovirus disease and asymptomatic infection on acute renal allograft rejection. J Clin Virol 2006;36:146-151.

5 Reischig T: Cytomegalovirus-associated renal allograft rejection: new challenges for antiviral preventive strategies. Expert Rev Anti Infect Ther 2010;8:903-910.

-6 Sagedal S, Nordal KP, Hartmann A, et al: The impact of cytomegalovirus infection and disease on rejection episodes in renal allograft recipients. Am J Transplant 2002;2: 850-856.

7 Humar A, Gillingham KJ, Payne WD, Dunn DL, Sutherland SER, Matas AJ: Association between cytomegalovirus disease and chronic rejection in kidney transplant recipients. Transplantation 1999;68:1879-1883.
-8 Reischig T, Jindra P, Hes O, Bouda M, Kormunda S, Treska V: Effect of cytomegalovirus viremia on subclinical rejection or interstitial fibrosis and tubular atrophy in protocol biopsy at 3 months in renal allograft recipients managed by preemptive therapy or antiviral prophylaxis. Transplantation 2009;87:436-444.

$\checkmark 9$ Das A: Cytomegalovirus infection in solid organ transplantation: economic implications. Pharmacoeconomics 2003;21:467475.

10 McCarthy JM, Karim MA, Krueger H, Keown PA: The cost impact of cytomegalovirus disease in renal transplant recipients. Transplantation 1993;55:1277-1282.

-11 Humar A, Snydman D, AST Infectious Diseases Community of Practice: Cytomegalovirus in solid organ transplant recipients. Am J Transplant 2009;9(suppl 4):S78-S86.

12 Kotton CN, Kumar D, Caliendo AM, et al: International consensus guidelines on the management of cytomegalovirus in solid organ transplantation. Transplantation 2010; 89:779-795.

13 Reischig T, Jindra P, Mares J, et al: Valacyclovir for cytomegalovirus prophylaxis reduces the risk of acute renal allograft rejection. Transplantation 2005;79:317-324.

14 Reischig T, Jindra P, Hes O, Svecová M, Klaboch J, Treska V: Valacyclovir prophylaxis versus preemptive valganciclovir therapy to prevent cytomegalovirus disease after renal transplantation. Am J Transplant 2008;8:6977.
15 Lowance D, Neumayer H-H, Legendre CM, et al: Valacyclovir for the prevention of cytomegalovirus disease after renal transplantation. N Engl J Med 1999;340:1462-1470.

16 Paya C, Humar A, Dominguez E, et al: Efficacy and safety of valganciclovir v.s. oral ganciclovir for prevention of cytomegalovirus disease in solid organ transplant recipients. Am J Transplant 2004;4:611-620.

17 Pavlopoulou ID, Syriopoulou VP, Chelioti H, et al: A comparative randomised study of valacyclovir vs. oral ganciclovir for cytomegalovirus prophylaxis in renal transplant recipients. Clin Microbiol Infect 2005;11:736743.

18 Khoury JA, Storch GA, Bohl DL, et al: Prophylactic versus preemptive oral valganciclovir for the management of cytomegalovirus infection in adult renal transplant recipients. Am J Transplant 2006;6:2134-2143.

19 Tilden DP, Chapman J, Davey PJ, Solly ML, Crowley S: A decision-analytic economic evaluation of valacyclovir prophylaxis for the prevention of cytomegalovirus infection and disease in renal transplantation. Clin Transplant 2004;18:312-320.

20 Legendre CM, Norman DJ, Keating MR: Valacyclovir prophylaxis of cytomegalovirus infection and disease in renal transplantation: an economic evaluation. Transplantation 2000;70:1463-1468.

21 Squifflet J, Legendre C: The economic value of valacyclovir prophylaxis in transplantation. J Infect Dis 2002;186(suppl 1):116-122. 
22 Hagenmeyer EG, Häussler B, Hempel E, et al: Resource use and treatment costs after kidney transplantation: impact of demographic factors, comorbidities, and complications. Transplantation 2004;77:1545-1560.

23 Kim WR, Badley AD, Wiesner RH, et al: The economic impact of cytomegalovirus unfection after liver transplantation. Transplantation 2000;69:357-361.

24 Schnitzler, MA, Lowell, JA, Hardinger KL, Boxerman SB, Bailey TC, Brennan DC: The association of cytomegalovirus sero-pairing with outcomes and costs following cadaveric renal transplantation prior to the introduction of oral ganciclovir CMV prophylaxis. Am J Transplant 2003;3:445-451.
25 Luan FL, Stuckey LJ, Park JM, Kaul D, Cibrik D, Ojo A: Six-month prophylaxis is cost effective in transplant patients at high risk for cytomegalovirus infection. J Am Soc Nephrol 2009;20:2449-2458.

26 Luan FL, Kommareddi M, Ojo AO: Universal prophylaxis is cost effective in cytomegalovirus serology-positive kidney transplant patients. Transplantation 2011;91:237-244.

27 Brennan DC, Garlock KA, Singer GG, et al: Prophylactic oral ganciclovir compared with deferred therapy for control of cytomegalovirus in renal transplant recipients. Transplantation 1997;64:1843-1846.

28 Legendre C, Beard SM, Crochard A, et al: The cost-effectiveness of prophylaxis with valacyclovir in the management of cytomegalovirus after renal transplantation. Eur J Health Econ 2005;6:172-182.
29 Paya C, Humar A, Dominiguez E, et al: Efficacy and safety of valganciclovir vs. oral ganciclovir for prevention of cytomegalovirus disease in solid organ transplant recipients. Am J Transplant 2004;4:611-620.

30 Humar A, Lebranchu Y, Vincenti F, et al: The efficacy and safety of 200 days valganciclovir cytomegalovirus prophylaxis in high-risk kidney transplant recipients. Am J Transplant 2010;10:1228-1237.

31 Blumberg EA, Hauser IA, Stanisic S, et al: Prolonged prophylaxis with valganciclovir is cost effective in reducing posttransplant cytomegalovirus disease within the United States. Transplantation 2010;90:1420-1426.

32 Opelz G, Döhler B: Influence of time of rejection on long-term graft survival in renal transplantation. Transplantation 2008;85: 661-666. 